\title{
Some Clinical, Psychological, Laboratory, and Genetic Aspects of Patients with Multiple Sclerosis in Upper Egypt
}

\author{
Hamdy Nageeb El Tallawy, Heba Mohamed Saad Eldin, Amal Mohamed Tohamy, Sara Eltellawy, Ali \\ Mabrouk Bathalath and Mohamed Mostafa Shehab*
}

Department of Neurology and Psychiatry, Assiut University, Egypt

*Corresponding author: Mohamed Mostafa Shehab, Department of Neurology and Psychiatry, Assiut University, Egypt.
Received Date: June 21,2021

Published Date: July 21, 2021

\begin{abstract}
Aim: Multiple sclerosis is the most prevalent chronic inflammatory disease of the central nervous system. The aim of the study is to show some clinical, cognitive, labarotory and genetic aspects in patients with multiple sclerosis in Upper Egypt.

Materials \& Methods: 40 patients with MS recruited along the period from Jan.1st 2017 to Dec.31st2017 and 40 healthy controls were included in the study. Clinical, cognitive (depression, anxiety, and sleep), laboratory (25-hydroxyvitamin D), and genetic (TMEM106B, APOE2, and APOE1) aspcts were assessed.
\end{abstract}

Results and conclusion: Low serum 25(OH) D level is a major risk factor for MS in Upper Egypt. Vitamin D deficiency increases the risk of developing depression in MS patients. APOE1, APOE2 polymorphism alone, does not affect MS susceptibility.

\section{Introduction}

Multiple sclerosis (MS) is the most prevalent chronic inflammatory disease of the central nervous system (CNS), affecting more than 2 million people worldwide (at least 400,000 in the United States), (Neurological Disorders Collaborator Group, 2015) [1]. It is punctuated by fully or partially reversible episodes of neurologic disability, usually lasting days or weeks. Manifestations at presentation include, but are not limited to, monocular visual loss due to optic neuritis, limb weakness or sensory loss due to transverse myelitis, double vision due to brain-stem dysfunction, or ataxia due to a cerebellar lesion [2]. With a prevalence of 50-300 per 100000 people, about $2 \cdot 3$ million people are estimated to live with MS globally [3]. The female to male sex ratio has increased markedly because of increased incidence of MS in women [4]. Most patients present in early adult life but there is increased awareness of presentation in childhood [5]. Interplay between environmental, genetic, and epigenetic factors have a causal role in MS [6]. Environmental risk factors such as vitamin D deficiency (either due to reduced exposure to sunlight or decreased natural production from sun exposure in ethnic groups with dark skin), diet, obesity in early life, and cigarette smoking may have a role in the development of MS [7]. Development of MS can also be associated with specific infections; for example, late infection as a young adult with EpsteinBarr virus increases the risk of subsequently developing the disease [8].

The increased heritability within families, and the directly proportional decrease in risk with degree of relatedness, provide evidence that genetic factors have a prominent role in the development of MS. Carriers of the HLA DRB1*15:01 allele 
are about three times more likely to develop MS than are noncarriers [9]. A genome-wide association study (GWAS) from 2017, identified 31 independent associations within the extended MHC region, including some within class I genes and the non-classical HLA region [10]. The HLA locus accounts for 20-30\% of the genetic susceptibility in MS [11]. In addition, GWAS showed that IL2RA and IL7RA re the first two non-HLA associations (International Multiple Sclerosis Genetics Consortium, 2007) [12]. Subsequent GWAS and a meta-analysis31 identified another dozen associations and brought the total number of associations to more than 200 [10].

Axonal or neuronal loss, demyelination, and astrocytic gliosis are the hallmarks of MS pathology which leads to permanent clinical disability. Axonal loss may occur not only acutely in new inflammatory lesions, but also more slowly over time in chronically demyelinated lesions [13,14]. Early MS is usually characterized by acute episodes of neurological deficits known as relapses, that depend on both the location of the CNS region affected by the acute inflammatory demyelinating lesions and the extent of the inflammatory process. Clinical deficits caused by acute inflammatory demyelination could be reversible via restoration of nerve conduction. The restored nerve conduction is more continuous than saltatory, and is achieved because of several changes following demyelination, such as an increase in sodium channels. In addition, remyelination leads to new myelinated internodes, although these are shorter and thinner than normal [15]. Recovery of clinical symptoms could also be secondary to remyelination and cortical plasticity [16,17], which consists of a reorganization of the functional activation of cortical regions to maintain clinical function [18].

Clinical, imaging, and laboratory findings should be integrated for diagnosis of MS. Clinical expertise and MRI are necessary to demonstrate evidence of dissemination in time and space and, importantly, to exclude other neurological conditions [19]. The diagnostic criteria, known as the McDonald Criteria, have evolved as technology has improved to refine definitions, become simpler, and more accessible and applicable to a larger proportion of the population while maintaining specificity and sensitivity $[20,13,14]$.

The majority of patients who develop MS begin with a single episode, termed a clinically isolated syndrome (CIS), and may have a second episode (or relapse), which marks the onset of clinically definite MS. Patients with at least 2 relapses are described as having relapsing remitting MS. $15 \%$ and $30 \%$ of them may develop progressive disability over a long-term follow-up, with or without superimposed relapses (described as secondary-progressive MS) [21,22]. About $15 \%$ of patients develop primary progressive MS from the outset [23]. Patients with incidental MRI findings consistent with MS, known as radiologically isolated syndrome (RIS), have been described [24]. 34\% of patients with RIS develop a first acute clinical event consistent with CIS or MS within 5 years [25].
Cognitive impairment is a common feature in MS affecting approximately $43 \%-72 \%$ of patients and involving cognitive functions, such as memory, processing speed, attention, and executive function [26]. Rocca et al. [27] investigated the dynamic interaction between cognitive reserve and global/regional measures of brain white matter and gray matter damage and their effect on cognitive performance in 54 MS patients and 20 healthy controls using baseline and two-year three-dimensional T1weighted scans. Initially, MS patients show atrophy of the deep gray matter nuclei, gray matter/white matter frontal-temporal-parietaloccipital regions, and left cerebellum [27].

In this study, clinical, imaging, and psychological assessment was done for MS patients. Cognitive functions, depression, anxiety, and sleep were assessed. Social support and psychological resilience were also assessed. Some biochemical tests and genetic analysis were done for patients and controls.

\section{Patients and Methods}

Forty patients with MS were recruited along the period from Jan.1st 2017 to Dec.31st2017 from inpatient neurology departments and outpatient neurology clinics of Assiut University hospitals in a multicenter case-control study.

Inclusion criteria: Patient were diagnosed according to revised McDonald's criteria (2017) [13,14]. The second group: 40 age and sex cross-matched healthy individuals were included as the control group.

Exclusion criteria: Patients proved to have autoimmune disease; Bechet disease and systemic lupus erythematosus and patients with other neurologic disorder mimic MS were excluded from the study.

\section{Methods}

Complete history taking, clinical examination and brain and spine magnetic resonance imaging with gadolinium enhancement were performed for all patients. Cognitive functions were assessed using Arabic form of Mini-mental state examination (MMSE) [28], the test was carried out as described in the original version [29], and Arabic version [30] of the Wechsler Adult Intelligence Scale-Revised (WAIS-R) [31]. Depression, anxiety, and sleep were assessed using Arabic version (West, 1985) of Beck Inventory Depression Score (BIDS), Arabic version of future anxiety scale, and Arabic version sleep disorder scale respectively. Arabic version of social support scale and psychological resilience scale were also applied to the patients. Patients were assessed using Timed 25-foot walk test and The Expanded Disability Status score (EDSS) [32]. Serum level of 25-hydroxyvitamin D was measured by enzyme linked immunosorbent assay (ELISA) technique. Genomic DNA was extracted from venous blood using a pure linked kit and the procedure recommended by the manufacturer (Vivantis). Extracted DNA was quantified using a nanodrop analyzer (ND-1000) spectrophotometer (Nanodrop Technologies Inc., Ortenberg, 
Germany) for TMEM106B (rs1990622), APOE2 (rs429358), and APOE1 (rs 7412). Polymorphisms were analyzed by an Taqman allelic discrimination assay according to manufacturer's protocol (Applied Biosystems, Stepone Plus). Genotyping was performed using real-time PCR with a thermal profile of $60^{\circ} \mathrm{c}$ for $30 \mathrm{sec}$., $95^{\circ} \mathrm{C}$ for $10 \mathrm{~min}, 95^{\circ} \mathrm{C}$ for $15 \mathrm{sec}^{\text {., and }} 60^{\circ} \mathrm{C}$ for $90 \mathrm{sec}$.

\section{Statistical Analysis}

Continuous data are expressed as the mean \pm standard

\section{Results}

Table 1: Baseline demographic data of MS patients.

\begin{tabular}{|c|c|c|c|c|c|c|}
\hline & & \multicolumn{2}{|c|}{ Cases } & \multicolumn{2}{|c|}{ Controls } & \multirow{3}{*}{ P-value } \\
\hline & \multicolumn{2}{|c|}{$(n=40)$} & \multicolumn{2}{|c|}{$(n=40)$} & & \\
\hline & No. & $\%$ & No. & $\%$ & & \\
\hline \multirow{2}{*}{ Sex: } & Male & 11 & 27.5 & 11 & 27.5 & \multirow{2}{*}{--} \\
\hline & Female & 29 & 72.5 & 29 & 72.5 & \\
\hline \multirow{4}{*}{ Age: (years) } & $<25$ & 12 & 30 & 11 & 27.5 & \multirow{3}{*}{--} \\
\hline & $25-30$ & 14 & 35 & 13 & 32.5 & \\
\hline & $>30$ & 14 & 35 & 16 & 40 & \\
\hline & Mean \pm SD & \multicolumn{2}{|c|}{$29.37 \pm 7.85$} & \multicolumn{2}{|c|}{$29.45 \pm 7.30$} & 0.965 \\
\hline \multirow{2}{*}{ Residence: } & Rural & 21 & 52.5 & -- & -- & \multirow{2}{*}{--} \\
\hline & Urban & 19 & 47.5 & -- & -- & \\
\hline \multirow{3}{*}{ Occupation: } & Working & 19 & 47.5 & -- & -- & \multirow{2}{*}{--} \\
\hline & Not working & 10 & 25 & -- & -- & \\
\hline & Housewife & 11 & 27.5 & & & -- \\
\hline \multirow{3}{*}{ Education: } & Low education & 10 & 25 & -- & -- & \multirow{3}{*}{--} \\
\hline & Middle education & 16 & 40 & -- & -- & \\
\hline & High education & 14 & 35 & -- & -- & \\
\hline \multirow{2}{*}{$\begin{array}{c}\text { Contraception use } \\
\text { among married } \\
\text { females }\end{array}$} & Yes & 2 & 5 & -- & -- & \multirow{2}{*}{--} \\
\hline & No & 38 & 95 & -- & -- & \\
\hline \multirow{2}{*}{ Smoking: } & Yes & 5 & 12.5 & -- & -- & \multirow{2}{*}{--} \\
\hline & No & 35 & 87.5 & -- & -- & \\
\hline \multirow{2}{*}{ Consanguinity: } & Yes & 7 & 17.5 & -- & -- & \multirow{2}{*}{--} \\
\hline & No & 33 & 82.5 & -- & -- & \\
\hline \multirow{2}{*}{ Family history of MS: } & Yes & 1 & 2.5 & -- & -- & \multirow{2}{*}{--} \\
\hline & No & 39 & 97.5 & -- & -- & \\
\hline \multirow{3}{*}{ Comorbidities: } & $\mathrm{DM}$ & 2 & 5 & -- & -- & \multirow{3}{*}{-- } \\
\hline & Drug abuse & 1 & 2.5 & -- & -- & \\
\hline & No & 37 & 92.5 & -- & -- & \\
\hline
\end{tabular}

$\mathrm{n}$ : number, \%: percentage

Table 2: Clinical data of MS patients.

\begin{tabular}{|c|c|c|c|}
\hline & & No. $(40)$ & $\%$ \\
\hline \multirow{5}{*}{ Duration of illness: } & Less than 1 year & 7 & 17.5 \\
\hline & $1-5$ years & 23 & 57.5 \\
\hline & More than 5 years & 10 & 25 \\
\hline & Mean \pm SD & \multicolumn{2}{|c|}{$4.56 \pm 5.75$} \\
\hline & Median (Range) & \multicolumn{2}{|c|}{$3.0(0.2-28.0)$} \\
\hline
\end{tabular}




\begin{tabular}{|c|c|c|c|}
\hline \multirow{4}{*}{ Age of onset: (years) } & $<20$ & 6 & 15 \\
\hline & $20-25$ & 21 & 52.5 \\
\hline & $>25$ & 13 & 32.5 \\
\hline & Mean \pm SD & \multicolumn{2}{|c|}{$24.83 \pm 6.80$} \\
\hline \multirow{5}{*}{ Total number of attacks: } & One attack & 16 & 40 \\
\hline & Two attacks & 10 & 25 \\
\hline & Three attacks or more & 14 & 35 \\
\hline & Mean \pm SD & \multicolumn{2}{|c|}{$2.60 \pm 2.09$} \\
\hline & Median (Range) & \multicolumn{2}{|c|}{$2.0(1.0-9.0)$} \\
\hline \multirow{3}{*}{ Course: } & Relapsing remitting & 35 & 87.5 \\
\hline & Secondary progressive & 1 & 2.5 \\
\hline & Primary progressive & 4 & 10 \\
\hline \multirow{4}{*}{ Time between first and second attack: (months) } & $<12$ & 11 & 45.8 \\
\hline & $\geq 12$ & 13 & 54.2 \\
\hline & Mean \pm SD & \multicolumn{2}{|c|}{$13.13 \pm 12.03$} \\
\hline & Median (Range) & \multicolumn{2}{|c|}{$12.0(3.0-60.0)$} \\
\hline \multirow{4}{*}{ Time between onset and diagnosis: (months) } & $<6$ months & 18 & 45 \\
\hline & $\geq 6$ months & 22 & 55 \\
\hline & Mean \pm SD & \multicolumn{2}{|c|}{$10.33 \pm 13.99$} \\
\hline & Median (Range) & \multicolumn{2}{|c|}{$6.0(1.0-60.0)$} \\
\hline \multirow{2}{*}{ 25-foot walk test impairment: } & Normal & 22 & 55 \\
\hline & Impaired & 18 & 45 \\
\hline
\end{tabular}

Table 3: Initial presenting symptoms of MS Patients.

\begin{tabular}{|c|c|c|}
\hline Initial presenting symptoms & No. (40) & \% \\
\hline INO & 13 & 32.5 \\
\hline Ataxia & 12 & 12.5 \\
\hline Motor weakness & 5 & 5 \\
\hline Trigeminal neuralgia & 2 & 2.5 \\
\hline optic neuritis with weakness & 1 & 5 \\
\hline ataxia with INO & 2 & 2.5 \\
\hline trigeminal neuralgia with INO & 1 & 10 \\
\hline INO with numbness & 4 & \\
\hline
\end{tabular}

Table 4: MRI findings in MS patients.

\begin{tabular}{|c|c|c|}
\hline MRI & No. (40) & \% \\
\hline Periventricular lesions & 40 & 100 \\
\hline Juxtacortical lesions & 39 & 97.5 \\
\hline Brainstem lesions & 17 & 42.5 \\
\hline Pericallosal lesions & 14 & 35 \\
\hline Cervical spine lesions & 9 & 22.5 \\
\hline Cerebellar lesions & 8 & 20 \\
\hline Enhancement lesions & 2 & 5 \\
\hline
\end{tabular}

Visual evoked potential was normal in 15 patients $(37.5 \%)$, while it showed mild, and moderate affection in 15 (37.5\%) and 10 (25\%) patients respectively. The mean MMSE score for MS patients was $28.58 \pm 0.96 .55 \%$ of MS patients had average IQ performance, the mean $89.78 \pm 10.01$. The verbal performance $67.5 \%$ was average, the mean was $91.95 \pm 9.75$ and total mean was 93.58 \pm 11.23 . There was significant correlation between MMSE and Wechsler performance score as shown in Figure 1 and Tables 7-10. 


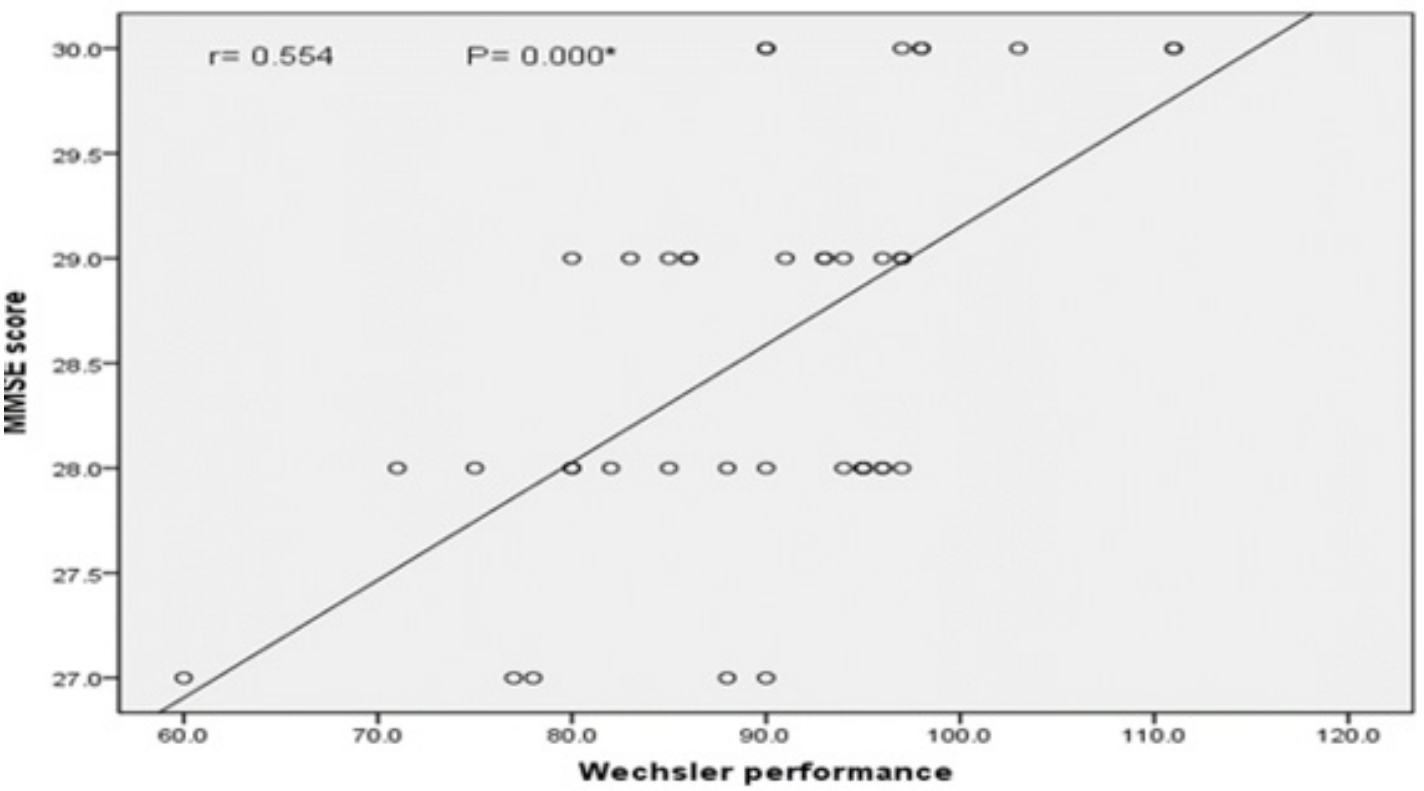

Figure 1: Correlation between MMSE and Wechsler performance score.

Table 5: Expanded disability status score (EDSS) groups.

\begin{tabular}{|c|c|c|}
\hline EDSS score & No. (40) & \% \\
\hline Mild (0-3) & 22 & 55 \\
\hline Moderate (3.5-5) & 5 & 12.5 \\
\hline Severe (6 and more) & 13 & 32.5 \\
\hline Mean \pm SD & & $4.05 \pm 2.47$ \\
\hline Median (Range) & \multicolumn{2}{|c|}{$3.0(1.0-8.0)$} \\
\hline
\end{tabular}

Table 6: Relation of degree of disability at time of interview to initial presenting symptom.

\begin{tabular}{|c|c|c|c|c|}
\hline \multicolumn{2}{|c|}{ Mild 0-3 (N=22) } & \multicolumn{2}{c|}{ EDSS SCORE } \\
\cline { 2 - 5 } & $\begin{array}{c}\text { Moderate 3.5-5 } \\
(\mathbf{N}=5)\end{array}$ & $\begin{array}{c}\text { Severe 6 and more (N= } \\
\text { 13) }\end{array}$ & \\
\hline \multirow{4}{*}{$\begin{array}{c}\text { Initial first presenting } \\
\text { symptoms }\end{array}$} & motor weakness (N=5) & $4(18.2 \%)$ & $0(0 \%)$ & $1(7.7 \%)$ \\
\cline { 2 - 5 } & Ataxia (N=12) & $4(18.2)$ & $2(40.0 \%)$ & $6(46.2 \%)$ \\
\cline { 2 - 5 } & INO (N=13) & $10(45.5 \%)$ & $2(40.0 \%)$ & $1(7.7 \%)$ \\
\cline { 2 - 5 } & trigeminal neuralgia (N=2) & $0(0 \%)$ & $0(0 \%)$ & $1(15.4 \%)$ \\
\cline { 2 - 5 } & optic neuritis with weakness (N=1) & $0(0 \%)$ & $0(0 \%)$ & $1(7.7 \%)$ \\
\cline { 2 - 5 } & ataxia with INO (N=2) & $0(0 \%)$ & $1(20.0 \%)$ & $1(7.7 \%)$ \\
\cline { 2 - 5 } & trigeminal neuralgia with INO (N=1) & $0(0 \%)$ & $0(0 \%)$ & $0(0 \%)$ \\
\hline
\end{tabular}

Table 7: Psychological resilience scale among studied MS patients and control groups.

\begin{tabular}{|c|c|c|c|c|c|c|}
\hline & & \multicolumn{2}{|c|}{ patients } & \multicolumn{2}{|c|}{ Controls } & \multirow{3}{*}{ P-value } \\
\hline & \multicolumn{2}{|l|}{$(n=40)$} & \multicolumn{2}{|c|}{$(n=40)$} & & \\
\hline & No. & $\%$ & No. & $\%$ & & \\
\hline \multirow{3}{*}{ Personal competence: } & Low (less than 29) & 40 & 100 & 0 & 0 & \multirow{2}{*}{$0.000^{*}$} \\
\hline & High (more than 29) & 0 & 0 & 40 & 100 & \\
\hline & Mean \pm SD & \multicolumn{2}{|c|}{$24.18 \pm 1.99$} & \multicolumn{2}{|c|}{$31.03 \pm 1.94$} & $0.000^{*}$ \\
\hline \multirow{3}{*}{ Problem solving: } & low (less than 24) & 39 & 97.5 & 1 & 2.5 & \multirow{2}{*}{$0.000^{*}$} \\
\hline & high (more than 24) & 1 & 2.5 & 39 & 97.5 & \\
\hline & Mean \pm SD & \multicolumn{2}{|c|}{$17.70 \pm 2.37$} & \multicolumn{2}{|c|}{$25.42 \pm 1.39$} & $0.000^{*}$ \\
\hline
\end{tabular}




\begin{tabular}{|c|c|c|c|c|c|c|}
\hline \multirow{3}{*}{ Flexibility: } & Low (less than 31) & 40 & 100 & 0 & 0 & \multirow{2}{*}{$0.000^{*}$} \\
\hline & High (more than 31) & 0 & 0 & 40 & 100 & \\
\hline & Mean \pm SD & \multicolumn{2}{|c|}{$24.17 \pm 1.41$} & \multicolumn{2}{|c|}{$35.28 \pm 2.64$} & $0.000^{*}$ \\
\hline \multirow{3}{*}{ Managing emotion: } & Low (less than 21) & 39 & 97.5 & 1 & 2.5 & \multirow{2}{*}{$0.000^{*}$} \\
\hline & High (more than 21) & 1 & 2.5 & 39 & 97.5 & \\
\hline & Mean \pm SD & \multicolumn{2}{|c|}{$16.80 \pm 2.03$} & \multicolumn{2}{|c|}{$23.15 \pm 1.89$} & $0.000^{*}$ \\
\hline \multirow{3}{*}{ Optimize: } & Low (less than 18) & 39 & 97.5 & 0 & 0 & \multirow{2}{*}{$0.000^{*}$} \\
\hline & High (more than 18) & 1 & 2.5 & 40 & 100 & \\
\hline & Mean \pm SD & \multicolumn{2}{|c|}{$15.52 \pm 2.76$} & \multicolumn{2}{|c|}{$20.02 \pm 1.48$} & $0.000^{*}$ \\
\hline \multirow{3}{*}{ Social relation: } & Low (less than 28) & 38 & 95 & 0 & 0 & \multirow{2}{*}{$0.000^{*}$} \\
\hline & High (more than 28) & 2 & 5 & 40 & 100 & \\
\hline & Mean \pm SD & \multicolumn{2}{|c|}{$24.90 \pm 1.26$} & \multicolumn{2}{|c|}{$30.38 \pm 1.71$} & $0.000^{*}$ \\
\hline \multirow{3}{*}{ Faith: } & Low (less than 30) & 40 & 100 & 0 & 0 & \multirow{2}{*}{$0.000^{*}$} \\
\hline & High (more than 30) & 0 & 0 & 40 & 100 & \\
\hline & Mean \pm SD & \multicolumn{2}{|c|}{$27.60 \pm 0.59$} & \multicolumn{2}{|c|}{$31.72 \pm 1.54$} & $0.000^{*}$ \\
\hline \multirow{3}{*}{ Total SRS: } & Low (less than 180) & 40 & 100 & 0 & 0 & \multirow{2}{*}{$0.000^{*}$} \\
\hline & High (more than 180) & 0 & 0 & 40 & 100 & \\
\hline & Mean \pm SD & \multicolumn{2}{|c|}{$150.35 \pm 5.04$} & \multicolumn{2}{|c|}{$197.00 \pm 5.80$} & $0.000^{*}$ \\
\hline
\end{tabular}

Table 8: Sleep disorders scale among studied MS patients and control groups.

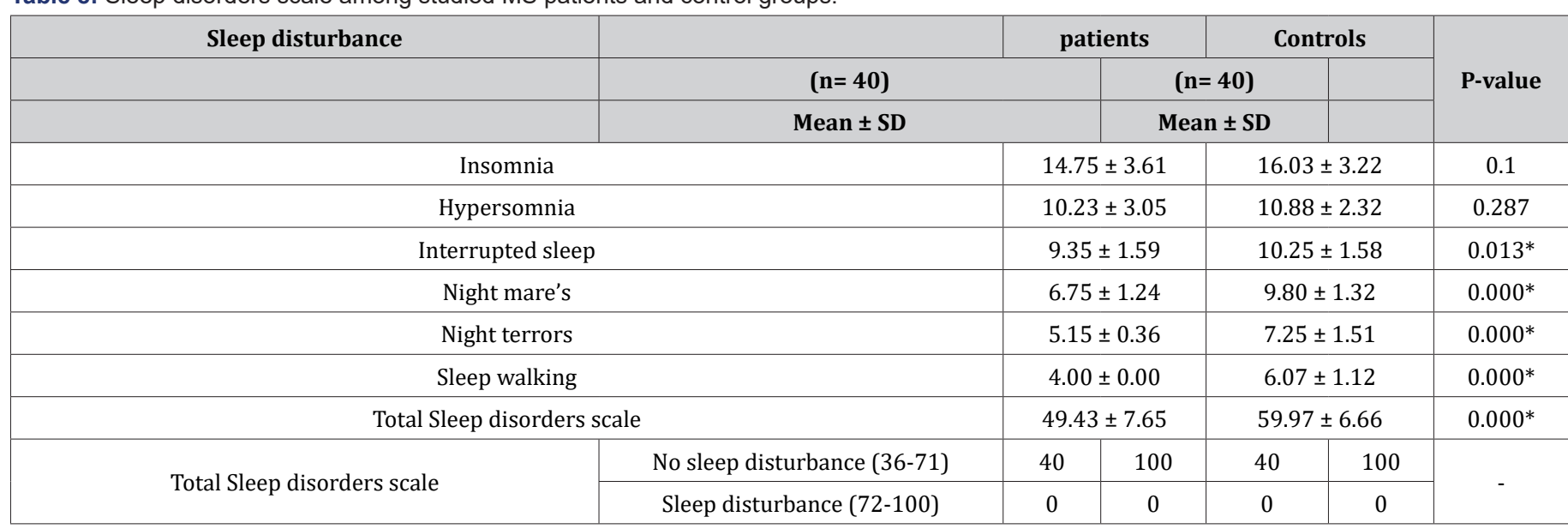

Table 9: Serum levels of 25-hydroxy vitamin among studied MS patients and control.

\begin{tabular}{|c|c|c|c|c|c|}
\hline \multirow{3}{*}{25 -hydroxy vit D } & \multirow{2}{*}{\multicolumn{2}{|c|}{$\begin{array}{c}\text { patients } \\
(n=40) \\
\end{array}$}} & \multirow{2}{*}{\multicolumn{2}{|c|}{$\begin{array}{l}\text { Controls } \\
(n=40)\end{array}$}} & \multirow{3}{*}{ P-value } \\
\hline & & & & & \\
\hline & No. & $\%$ & No. & $\%$ & \\
\hline Sufficient $(30-100 \mathrm{ng} / \mathrm{ml})$ & 2 & 5 & 14 & 35 & \multirow{3}{*}{$0.000^{*}$} \\
\hline Insufficient (10-29 ng/ml) & 27 & 67.5 & 26 & 65 & \\
\hline Deficient $(<10 \mathrm{ng} / \mathrm{ml})$ & 11 & 27.5 & 0 & 0 & \\
\hline Mean \pm SD & \multicolumn{2}{|c|}{$14.59 \pm 9.40$} & \multicolumn{2}{|c|}{$31.10 \pm 7.19$} & \multirow{2}{*}{$0.000^{*}$} \\
\hline Median (Range) & \multicolumn{2}{|c|}{$12.0(5.0-50.0)$} & \multicolumn{2}{|c|}{$29.0(21.0-50.0)$} & \\
\hline
\end{tabular}

Table 10: Genetic analysis of APOE1, APOE2 and TMEM106B among MS patients and control groups.

\begin{tabular}{|c|c|c|c|c|c|c|}
\hline & & \multicolumn{2}{|c|}{ patients } & \multicolumn{2}{|c|}{ Controls } & \multirow{3}{*}{ P-value } \\
\hline & \multicolumn{2}{|c|}{$(n=40)$} & \multicolumn{2}{|c|}{$(n=40)$} & & \\
\hline & No. & $\%$ & No. & $\%$ & & \\
\hline \multirow{3}{*}{ APOE1: } & Homogenous $1=\mathrm{CC}=$ wild & 38 & 95 & 33 & 82.5 & \\
\hline & Homogenous $2=\mathrm{TT}=$ mutant & 0 & 0 & 0 & 0 & \\
\hline & Heterogeneous $=\mathrm{CT}=$ carrier & 2 & 5 & 7 & 17.5 & \\
\hline
\end{tabular}




\begin{tabular}{|c|c|c|c|c|c|c|}
\hline \multirow{3}{*}{ APOE2: } & Homogenous1=CC= wild & 2 & 5 & 0 & 0 \\
\cline { 2 - 7 } & Homogenous2=TT= mutant & 38 & 95 & 40 & 100 \\
\cline { 2 - 7 } & Heterogeneous= CT=carrier & 0 & 0 & 0 & 0 \\
\hline \multirow{3}{*}{ TMEM106B: } & Homogenous1= CC=mutant & 1 & 2.5 & 6 & 15 \\
\cline { 2 - 7 } & Homogenous2= TT=wild & 33 & 82.5 & 34 & 85 \\
\cline { 2 - 7 } & Heterogeneous= CT=carrier & 6 & 15 & 0 & 0 \\
\hline
\end{tabular}

\section{Discussion}

Multiple sclerosis (MS) is a progressive demyelinating and neurodegenerative disease of the central nervous system (CNS). The pattern of symptoms of MS is complex, variable and unpredictable. MS has sensorimotor, cognitive, affective, autonomic, special sense, and many other manifestations. This study tried to show the various manifestations of MS in a group of 40 patients with studying some biochemical and genetic aspects.

The female: male ratio was 2.9:1. This is in agreement with many previous studies, which showed that MS is more prevalent in the female more than male similar to the corresponding ratios measured previously in Egypt 2.57:1 (Zakaria et al., 2016). For unknown reasons, approximately three quarters of people with multiple sclerosis are female, as is common in diseases that are considered autoimmune [33]. The range of age of the patient with MS was 17-48 years (29.37 \pm 7.85$)$. These results agree with many other studies such as Tutuncu et al, (2013) [34] that found most individuals are diagnosed with MS at age 20-50 years [34].

In this study, 35 patients (87.5\%) presented with relapsing remitting course, 4 patients (10\%) presented with primary progressive course and 1 patient $(2.5 \%)$ presented with secondary progressive course. Tamás Biernacki et al. [35] showed that $65.71 \%$ of their patients had relapsing-remitting course, $24.29 \%$ had secondary progressive course, $7.14 \%$ had primary progressive disease course and $2.86 \%$ patients were diagnosed with CIS [35]. In this study, only one male patient has positive family history of MS (his sister). Akkad et al. study reported that the risk of MS incidence in first-degree relatives is increased (3.4-5.13\%) in Canada, England, Scotland and Belgium. Twin studies demonstrated genetic susceptibility in monozygotic twins with $25-30 \%$ concordance rate and $0.25-0.76$ heritability index [36]. The most frequent neurologic manifestations along whole MS course were motor manifestations (57.5\%), followed by sensory manifestations (55\%). 15\% of patients had manifestations of optic nerve affection. Azadvari et al (2020) in their study showed that $28 \%$ of MS patients suffering from neurogenic bladder are of older age or have longer duration of disease [37]. The mean EDSS score of patients was $4.05 \pm 2.47$ (Table 5). It is nearly similar to a new registry in Egypt (3.6) as reported by (Zakaria et al., 2016). It was nearly similar to that reported in North Tonawanda, the mean of EDSS was $5.02 \pm 1.67$ [38]. The mean MMSE score for MS patients was $28.58 \pm 0.96$. These results agree with Shamsian et al. [39] where the mean of MMSE score was $27.23 \pm 3.27$ in MS patients compared to $28.96 \pm$
2.00 in control group [39]. Beck Depression Inventory (BDI) score was significantly higher in all types of MS patients in comparison to control group. $82.5 \%$ of MS patients had depression with different degrees of severity with $25 \%$ of patients had severe depression. The mean of the patients was $21.90 \pm 9.61$. There was positive significant correlation between depression assessed by BDI score and MS disability assessed by EDSS. This is in agreement with many other studies $[40,41]$.

Future Anxiety Scale was significantly higher in all types of MS patients in comparison to control group. The mean of total future Anxiety Scale for patients was $51.35 \pm 11.85$. Wallis et al. [42] found that almost half of the patients $(42 \%)$ had clinically significant anxiety symptoms. Wallis et al. [42] Other studies also reported that anxiety and depression are very prevalent in MS patients. Prevalence of both conditions range between $25-50 \%$, which is much higher than the general population $[43,44]$.

Social support scale was significantly higher in family support and in total social support among MS patients with comparison to control group. The mean of social support in family for patients $59.18 \pm 11.54$. In addition, the mean for control $70.75 \pm 5.66$. Also the mean of total support for the patient is $125.85 \pm 20.56$. Also there was significant correlation between Social support scale in family support and out family support among patients and level of education. Mikula et al. [45] suggested that social support may had a buffering effect, and that in case of a long-term health threatening condition, social support from family, friends, and significant others may protect MS patients from more severe depression [45]. Psychological resilience scale was significantly lower in all types of MS patients in comparison with control group (P. value $0.000^{*}$ ). Another study, included 185 patients with early MS, showed that high psychological resilience was associated with better objective performance on the MS and motor outcomes, especially gross motor function (i.e. grip strength, gait endurance). This relationship of psychological resilience to outcomes was independent of mood and fatigue [46].

Garland et al. [47] have found sleep disorders to be four times higher in patients with MS as compared to healthy populations [47]. In a previous Chinese study, Sleep disorders among patients with MS was $64.9 \%$ [48]. In this study, levels of vitamin D among total and all phenotypes of MS patients (14.59 \pm 9.40) were significantly lower than controls (31.10 \pm 7.19$)$. Zamazam et al. $[49,50]$ studied the status of vitamin D in MS Egyptian patients and reported a significant vitamin D insufficiency in Egyptian patients 
with MS (65.7\%) as well as in controls 21.2\% [49,50]. Behrens et al. [51] reported vitamin D deficiency already in very early phases of MS [51]. A cross-sectional study of 50 RRMS patients revealed a vitamin D deficiency with a mean of $22.3 \mathrm{ng} / \mathrm{ml} / \mathrm{ml}$ [52]. In a Moroccan study of 113 MS patients, $97.3 \%$ of patients were vitamin D deficient with a mean of $11.69 \mathrm{ng} / \mathrm{ml}$ [53]. Bäcker-Koduah et al. [54] found vitamin D deficiency is common in RRMS patients living in the north-eastern part of Germany [54]. There is an ongoing debate whether vitamin D deficiency represents a risk factor for MS or whether this association is rather due to reverse causality, i.e., low vitamin D levels are a result of MS, for example as a consequence of reduced outdoor activities. In a study on a different cohort of early MS or CIS patients, there was vitamin D deficiency already in very early phases of MS [51] which also supports the interpretation that vitamin D deficiency is rather a cause than a consequence of MS.

In the current study, a negative but insignificant correlation was found between serum level vitamin D and disease disability as measured by EDSS. Our results agreed with Rito et al. [52] who found no correlation between vitamin D levels and EDSS scores, or duration of disease. The lack of significance in our study might be related to small sample size and the reliance on EDSS only as a marker for disease severity. In our study, the more deficient 25 hydroxy Vitamin D, the more severity of depression. This agree with Kotb et al. [41] who demonstrated that lower vitamin D levels are associated with higher depressive scores.

In the present study, there were significant difference between patients and controls regarding TMEM106B gene (P-value .008). There was no significant difference between patients and controls regarding APOE1 and APOE2 genes. These results agree with many other studies for APOE1 and APOE2 such as Flowers et al (2020) and Yamazakiet al $(2019)[55,56]$ who found that APOE alleles are not associated with MS risk or severity [55,56]. Schrewe et al. [57] studied linear regression analyses of MS and APOE rs7412 and rs429358. In the overall analyses, 3237 MS patients did not reveal statistically significant association with MS severity and APOE [57]. A total of 552 participants from the German National MS cohort, a multicenter, prospective, and observational study, were included. The putative role of APOE polymorphisms on the cognitive outcome parameters in patients with MS had been assessed. Neither APOE2 carrier status nor APOE4 heterozygosity showed an influence on the evaluated cognitive outcome parameters $[58,59]$

\section{Conclusion}

In conclusion, the most robust predictor of MS disability is MS course outcomes. Low serum 25(OH) D level is a major risk factor for MS in Upper Egypt. Vitamin D deficiency increases the risk of developing depression in MS patients. APOE1, APOE2 polymorphism alone, does not affect MS susceptibility as we cannot exclude other HLAG polymorphic sites which may work together to regulate MS risk. Further studies on larger number of are needed to study the role of TMEM106B gene polymorphism in pathogenesis of MS. This study highlights the importance of focusing research on identifying different clinical, psychological, biochemical, and genetic biomarkers capable of characterizing the course and severity of MS.

\section{Acknowledgement}

None.

\section{Conflict of Interest}

No conflict of interest.

\section{References}

1. GBD 2015 Neurological Disorders Collaborator Group (2017) Global, regional, and national burden of neurological disorders during 19902015: a systematic analysis for the Global Burden of Disease Study 2015. Lancet Neurol 16: 877-97.

2. Brownlee WJ, Hardy TA, Fazekas F, Miller DH (2017) Diagnosis of multiple sclerosis: progress and challenges. Lancet 389: 1336-1346.

3. Browne P, Chandraratna D, Angood C, Helen Tremlett, Chris Baker, et al. (2014) Atlas of multiple sclerosis 2013: a growing global problem with widespread inequity. Neurology 83: 1022-1024.

4. Orton SM, Herrera BM, Yee IM, William Valdar, Sreeram V Ramagopalan, et al. (2006) Sex ratio of multiple sclerosis in Canada: a longitudinal study. Lancet Neurol 5: 932-36.

5. Krupp LB, Tardieu M, Amato MP, Brenda Banwell, Tanuja Chitnis, et al. (2013) International Pediatric Multiple Sclerosis Study Group criteria for pediatric multiple sclerosis and immune-mediated central nervous system demyelinating disorders: revisions to the 2007 definitions. Mult Scler 19: 1261-67.

6. Olsson T, Barcellos LF, Alfredsson L (2017) Interactions between genetic, lifestyle and environmental risk factors for multiple sclerosis. Nat Rev Neurol 13: 25-36.

7. Marrie RA (2004) Environmental risk factors in multiple sclerosis aetiology. Lancet Neurol 3: 709-18.

8. Levin LI, Munger KL, Rubertone MV, Charles A Peck, Evelyne T Lennette, et al. (2005) Temporal relationship between elevation of Epstein-Barr virus antibody titers and initial onset of neurological symptoms in multiple sclerosis. JAMA 293: 2496-500.

9. Patsopoulos NA, Barcellos LF, Hintzen RQ Catherine Schaefer, Cornelia $M$ van Duijn, et al. (2013) Fine-mapping the genetic association of the major histocompatibility complex in multiple sclerosis: HLA and nonHLA effects. PLoS Genet 9: e1003926.

10. Patsopoulos N, Baranzini SE, Santaniello A, et al. (2017) The Multiple Sclerosis Genomic Map: Role of peripheral immune cells and resident microglia in susceptibility. BioRxiv.

11. Haines JL, Terwedow HA, Burgess K, M A Pericak-Vance, J B Rimmler, et al. (1998) Linkage of the MHC to familial multiple sclerosis suggests genetic heterogeneity. The Multiple Sclerosis Genetics Group. Hum Mol Genet 7: 1229-34.

12. International Multiple Sclerosis Genetics Consortium, Hafler DA Compston A, Stephen Sawcer, Eric S Lander, Mark J Daly, et al. (2007) Risk alleles for multiple sclerosis identified by a genomewide study. N Engl J Med 357: 851-62.

13. Thompson AJ, Banwell BL, Barkhof F, William M Carroll, Timothy Coetzee, et al. (2018) Diagnosis of multiple sclerosis: 2017 revisions of the McDonald criteria. Lancet Neurol 17: 162-173.

14. Thompson AJ, Baranzini SE, Geurts J, Hemmer B, Ciccarelli (2018) Multiple sclerosis. The Lancet 391(10130).

15. Franklin RJ, Ffrench-Constant C (2008) Remyelination in the CNS: from biology to therapy. Nat Rev Neurosci 9: 839-55.

16. Irvine KA, Blakemore WF (2008) Remyelination protects axons from demyelination-associated axon degeneration. Brain 131: 1464-77. 
17. Tomassini V, Matthews PM, Thompson AJ, Daniel Fuglø, Jeroen J Geurts, et al. (2012) Neuroplasticity and functional recovery in multiple sclerosis. Nat Rev Neurol 8: 635-646.

18. Jenkins TM, Toosy AT, Ciccarelli O, Katherine A Miszkiel, Claudia A Wheeler-Kingshott, et al. (2010) Neuroplasticity predicts outcome of optic neuritis independent of tissue damage. Ann Neurol 67: 99-113.

19. Brownlee WJ, Swanton JK, Altmann DR, Ciccarelli O, Miller DH (2015) Earlier and more frequent diagnosis of multiple sclerosis using the McDonald criteria. J Neurol Neurosurg Psychiatry 86: 584-85.

20. Polman CH, Reingold SC, Banwell B, Michel Clanet, Jeffrey A Cohen, et al. (2011) Diagnostic criteria for multiple sclerosis: 2010 revisions to the McDonald criteria. Ann Neurol 69: 292-302.

21. Cree BA, Gourraud PA, Oksenberg JR, et al. (2016) Long-term evolution of multiple sclerosis disability in the treatment era. Ann Neurol 80 499-510.

22. Lorscheider J, Buzzard K, Jokubaitis V, Tim Spelman, Eva Havrdova, et al. (2016) Defining secondary progressive multiple sclerosis. Brain 139 2395-405.

23. Miller DH, Leary SM (2007) Primary-progressive multiple sclerosis. Lancet Neurol 6: 903-912.

24. Labiano-Fontcuberta A, Benito-León J (2016) Radiologically isolated syndrome: An update on a rare entity. Mult Scler 22: 1514-1521.

25. Okuda DT, Siva A, Kantarci O, Matilde Inglese, Ilana Katz, et al. (2014) Radiologically isolated syndrome: 5-year risk for an initial clinical event PLoS One 9: e90509.

26. Trenova AG, Slavov GS, Manova MG, Aksentieva JB, Miteva LD, et al. (2016) Cognitive impairment in multiple sclerosis. Folia Med (Plovdiv) 58(3): 157-163.

27. Rocca MA, Riccitelli GC, Meani A, Pagani E, Del Sette P, Martinelli V, et al. (2018) Cognitive reserve, cognition, and regional brain damage in MS: A 2 -year longitudinal study. Mult Scler 1:1352458517750767.

28. El Okl M (2002) Prevalence of Alzheimer dementia and other causes of dementia in Egyptian elderly [Dissertation]. Cairo: Ain Shams University.

29. Folstein MF, Folstein SE, McHugh PR (1975) "Mini-mental state": a practical method for grading the cognitive state of patients for the clinician. Journal of psychiatric research 12:189-198.

30. Melika L (1996) Wechsler Adult Intelligence Scale-revised manual. In Arabic examiner's handbook: Dar Egyptian Books House Cairo.

31. Wechsler D, De Lemos MM (1981) Wechsler adult intelligence scalerevised: Harcourt Brace Jovanovich.

32. Kurtzke JF (2015) Further to the origin of EDSS (Response to: L. Kappos et al: "On the origin of Neurostatus" Multiple Sclerosis and Related Disorders 4: 186). Multiple Sclerosis and Related Disorders 4(3): 186

33. Reich DS, Lucchinetti CF, Calabresi PA (2018) Multiple sclerosis. New England Journal of Medicine, 378(2): 169-180.

34. Tutuncu M, Junger Tang, Nuhad Abou Zeid, Nilufer Kale, Daniel J Crusan, et al. (2013) Onset of progressive phase is an age- dependent clinical milestone in multiple sclerosis. Mult Scler 19: 188-198.

35. Tamás Biernacki, Dániel Sandi, Zsanett Fricska-Nagy, Zsigmond Tamás Kincses, Judit Füvesi, et al. (2020) Epidemiology of multiple sclerosis in Central Europe, update from Hungary. Brain and Behavior 10(5): e01598.

36. Akkad DA, Lee DH, Bruch Km, Aiden Haghikia, Jörg T Epplen, et al, (2016) Multiple sclerosis in families: risk factors beyond known genetic polymorphisms. Neurogenetics 17: 131-135.

37. Azadvari M, Razavi SZ, Shahrooei M, Moghadasi AN, Azimi A, et al. (2020) Bladder Dysfunction in Iranian Patients with Multiple Sclerosis. Journal of Multidisciplinary Healthcare 13: 345-349.

38. Susan E Bennett, Lacey E Bromley, Nadine M Fisher, Machiko R Tomita, Paulette Niewczyk (2017) Validity and Reliability of FourClinical Gait
Measures in Patients with Multiple Sclerosis. Int J MS Care 19(5): 247252.

39. Shamsian F, Dastjerdi RM, Kavosh A, Ashtari F (2019) Naming error in multiple sclerosis patients: A pilot study in Isfahan, Iran.

40. Nabavi SM, Tahbaz S, Salahesh A, Behjati Z, Nourbala F, Sadeghi S, Saeedi Z, Morsali D, Haghani S (2016) Correlation between Cognitive Functions, Fatigue, Depression and Disability Status in a Cohort of Multiple Sclerosis Patients. World Journal of Neuroscience 6: 208.

41. Kotb MA, Kamal AM, Aldossary NM, Bedewi MA (2019) Effect of vitamin $\mathrm{D}$ replacement on depression in multiple sclerosis patients. Multiple sclerosis and related disorders 29:111-117.

42. Wallis O, Bol Y, Köhler S, van Heugten C (2019) Anxiety in MS is related to depressive symptoms and cognitive complaints. Acta Neurologica Scandinavica.

43. Morrow SA, Rosehart H, Pantazopoulos K (2016) Anxiety and depressive symptoms are associated with worse performance on objective cognitive tests in MS. J Neuropsychiatr Clin Neurosci 28: 118-123.

44. Boeschoten, RE, Braamse, AMJ, Beekman, ATF, Pim Cuijpers, Patricia van Oppen, et al. (2017) Prevalence of depression and anxiety in multiple sclerosis: a systematic review and meta-analysis. J Neurol Sci 372: 331341.

45. Mikula P, Timkova V, Linkova M, Vitkova M, Szilasiova J, et al. (2020) Fatigue and suicidal ideation in people with multiple sclerosis, The role of social support Front Psychol 11: 504

46. Klineova S, Brandstadter R, Fabian MT, Sand IK, Krieger S, et al. (2019) Psychological resilience is linked to motor strength and gait endurance in early multiple sclerosis Mult Scler 26(9):1111-1120.

47. Garland SN, Scurrey SRM, Ploughman M, Health, Lifestyle and Aging with MS Canadian Consortium (2017) Aging with MSCC. Factors associated with poor sleep in older adults with multiple sclerosis. Int J Behav Med 24: 937-945.

48. Ma S, Rui X, Qi P, Liu G, Yang J (2016) Sleep disorders in patients with multiple sclerosis in China. Sleep and Breathing 21(1): 149-154.

49. Zakaria M, Zamzam DA, Abdel Hafeez MA, Swelam MS, Khater SS, et al. (2016) Clinical characteristics of patients with multiple sclerosis enrolled in a new registry in Egypt. Multiple sclerosis and related disorders 10: 30-35.

50. Zamzam D, Fouad M, Elaidy D, Abd-Elaziz D, Abd-Elaziz A (2016) Vitamin D levels in a sample of Egyptian patients with multiple sclerosis. Egypt ] Neurol Psychiatry Neurosurg 53(2): 107.

51. Behrens JR, Rasche L, Gieß RM, Pfuhl C, Wakonig K, et al. (2016) Low25-hydroxyvitamin $\mathrm{D}$, but not the bioavailable fraction of 25-hydroxyvitaminD, is a risk factor for multiple sclerosis. Eur J Neurol 23: $62-7$.

52. Rito Y, Flores J, Fernandez-Aguilar A, Escalante-Membrillo C, Barboza MA, et al. (2018) Vitamin D and disability in relapsing-remitting multiple sclerosis in patients with a Mexican background. Acta neurologica Belgica 118: 47-52

53. Skalli A, Haddou EAB, El Jaoudi R, Razine R, Mpandzou G, et al. (2018) Association of vitamin D status with multiple sclerosis in a case-control study from Morocco. Revue neurologique 174: 150-156.

54. Bäcker-Koduah P, Bellmann-Strobl J, Scheel M, Wuerfel J, Wernicke K, et al. (2020) Vitamin D and disease severity in multiple sclerosis-baseline data from the randomized controlled Trial (EVIDIMS). Front Neurol 11: 129.

55. Flowers SA, Rebeck GW (2020) APOE in the normal brain. Neurobiol Dis 136: 104724

56. Yamazaki Y, Zhao N, Caulfield TR, Chia-Chen Liu, Guojun Bu (2019) Apolipoprotein E and Alzheimer disease: Pathobiology and targeting strategies. Nat Rev Neurol 15(9): 501-518.

57. Schrewe L, Lill CM, Liu T, Salmen A, Gerdes LA, et al. (2015) Investigation of sex-specific effects of apolipoprotein E on severity of EAE and MS Journal of Neuroinflammation 12: 234. 
58. Engel S, Graetz C, Salmen A, Muthuraman M, Toenges G, Ambrosius B (2020) Is APOE $\varepsilon 4$ associated with cognitive performance in early MS.
59. Beck AT (1978) Depression inventory. Philadelphia: Center for Cognitive Therapy 72 